\title{
The Influence of Test Duration and Geometry on the Creep Crack Initiation and Growth Behaviour of 316H Steel
}

\author{
C. M. Davies ${ }^{1 *}$, D. W. Dean ${ }^{2}$, M. Yatomi ${ }^{3}$ and K. M. Nikbin ${ }^{1}$ \\ ${ }^{1}$ Dept. Mechanical Engineering, Imperial College London, South Kensington Campus, London, SW7 2AZ, UK. \\ ${ }^{2}$ British Energy Generation Ltd, Gloucester, GL4 3RS, UK. \\ ${ }^{3} \mathrm{IHI}$ Corporation, Shinnakahara-cho, Isogo-ku, Yokohama, 235-8501 Japan.
}

Abstract

Short term creep crack growth (CCG) tests have often been performed so that they may be incorporated into research projects with a relatively narrow time frame. Therefore tests are generally performed at relatively high loads, leading to high values of the crack tip driving force parameter $C^{*}$, to reduce the test duration. For the case of ductile materials with relatively low yield strengths, this can lead to significant plastic strains being generated in the specimen on loading. Recently, long term CCG tests have been performed on the low constraint double edge notch tension and high constraint compact tension specimen geometries of $316 \mathrm{H}$ stainless steel at $550{ }^{\circ} \mathrm{C}$. The CCG test data is examined in terms of the experimentally determined $C^{*}$ parameter and compared to data available from a wide range of specimen geometries over a range of $C^{*}$ values. At high $C^{*}$ values similar CCG behaviour is observed for the various specimen geometries. A difference in CCG behaviour is observed between long and short term tests on the compact tension geometry which may be explained by the effects of constraint loss due to plasticity effects. However, similar trends are observed in the CCG rate data of the alternative, relatively lower constrained geometries, at both high and low $C^{*}$ values. The influence of test duration and specimen geometry on creep crack initiation (CCl) times is also studied and experimental results are compared to predictions from analytical models.

\section{Keywords}

Creep crack growth, creep crack initiation, specimen geometry, constraint effects, $316 \mathrm{H}$ steel

\section{Introduction}

Creep crack initiation $(\mathrm{CCl})$ and subsequent growth $(\mathrm{CCG})$ is a principal failure mechanism of components operating at elevated temperatures. Safe and accurate methods to predict $\mathrm{CCl}$ and $\mathrm{CCG}$ are therefore

\footnotetext{
* Corresponding author

Tel: $+44(0) 2075940932$

Fax: $+44(0) 2075947017$

E-mail address: catrin.davies@imperial.ac.uk
} 
required in order to assess the reliability of such components. Experimental CCI and CCG tests are essential to enable material and geometry behaviour to be determined and models to be verified. Various specimen geometries, such as the Single Edge Notched specimen in Tension, SEN(T), and Bending, SEN(B), the Double Edge Notched specimen in Tension, $\mathrm{DEN}(\mathrm{T})$, the Middle cracked specimen in Tension, $\mathrm{M}(\mathrm{T})$, and the C-Shaped specimen in Tension, CS(T), may be more suitable under certain circumstances, due to e.g. material or equipment availability or the need for comparability of specimen crack tip constraint with in-service conditions. To date, creep crack initiation and growth tests have been of relatively short test duration, typically less that $4000 \mathrm{hrs}$ (approximately six months), so that results can be obtained within a practicable time scale. Generally this means that for ductile materials such as austenitic Type $316 \mathrm{H}$ stainless steel, the load applied to the specimen generates a reference stress in excess of the yield stress of the material, which implies that significant plasticity is introduced into the test specimens on loading. Recently, long term tests (of duration exceeding $16,000 \mathrm{hrs}$ ) have been performed on two compact tension, $\mathrm{C}(\mathrm{T})$, specimens [1] and on a DEN(T) specimen of Type $316 \mathrm{H}$ stainless steel at $550{ }^{\circ} \mathrm{C}$. The $\mathrm{C}(\mathrm{T})$ specimen, which is subjected to combined bending and tension loading is generally considered to be a high constraint geometry in comparison to specimens under predominantly tensile loading such as the $M(T)$ and $D E N(T)$ whereas the $\operatorname{SEN}(B)$ and $C S(T)$ have intermediate levels of constraint. The $C C I$ and $C C G$ data from this long term $\mathrm{DEN}(\mathrm{T})$ specimen test have been analysed in terms of the $C^{*}$ parameter, according to the procedure specified in [2], and compared to results from short term $\mathrm{DEN}(\mathrm{T})$, long term $\mathrm{C}(\mathrm{T})$, and shorter term tests on a variety of specimen geometries, and also to CCI and CCG models.

\section{Crack Initiation and Growth Behaviour and Models}

In polycrystalline materials under stress at high temperatures, a zone of creep deformation and damage (in the form of voids and micro-cracks) will develop initially ahead of a stress concentration feature such as a notch or crack tip. For many materials under steady state conditions, the creep strain rate, $\dot{\varepsilon}$, may be related to the stress, $\sigma$, by the power-law expression,

$$
\dot{\varepsilon}=A \sigma^{n}
$$

where $n$ and $A$ are the power-law creep stress exponent and coefficient, respectively. At long times, where a steady state of creep deformation and damage has developed at a crack tip, the CCI time, $t_{i}$, and CCG rate, $\dot{a}$, may be described by the $C^{*}$ parameter, and $\dot{a} v s . C^{*}$ data appear as a straight line on log-log axes, 


$$
\dot{a}=D C^{* \phi}
$$

where $D$ and $\phi$ are material constants, which may be temperature and stress state dependent [3]. Prior to steady state conditions being achieved, data points will appear as a 'tail' on the $\dot{a} v s . C^{*}$ plot. Validity criteria for the $\dot{a}$ vs. $C^{*}$ correlation are specified in [4].

\subsection{Crack Initiation and Growth Models}

The NSW-MOD model [5] has been derived to predict the CCG rate under steady state creep conditions and considers the dependence of creep strain on both the crack tip angle, $\theta$, and the creep stress exponent, $n$, in addition to the stress state. Crack growth is considered to occur when a critical quantity of damage, measured by a creep ductility exhaustion approach, is attained at a characteristic distance, $r_{c}$, ahead of the crack tip. The steady state creep crack growth rate prediction from this model is given by

$$
\dot{a}=\left.(n+1)\left(A r_{c}\right)^{\frac{1}{n+1}}\left[\frac{C^{*}}{I_{n}}\right]^{\frac{n}{n+1}} \frac{\tilde{\varepsilon}_{e q}(\theta, n)}{\varepsilon_{f}^{*}(\theta, n)}\right|_{\max }
$$

Crack growth is predicted using the maximum value of the angular function $\tilde{\varepsilon}_{e q} / \varepsilon_{f}^{*}$, where $\tilde{\varepsilon}_{e q}$ is a non dimensional function of $\theta$ and $n$. In Eqn (3) $I_{n}$ is a non dimensional function of $n$. Values for $\tilde{\varepsilon}_{e q}$ and $I_{n}$ are tabulated in [6]. The value of the multiaxial ductility, $\varepsilon_{f}^{*}$, for a range of stress states may be estimated from the uniaxial failure strain, $\varepsilon_{f}$, using an appropriate model, such as the Cocks and Ashby void growth and coalescence model [7] used in this study. The distance $r_{c}$ is generally taken to be the grain size of the material. The $\mathrm{CCl}$ time, defined as the time for a small measurable crack extension, $\Delta a$, may be estimated by assuming that the crack grows from the point of initial loading at a constant rate. Lower and upper bound estimates of the $\mathrm{CCl}$ time may be obtained using either the steady state CCG rate, $\dot{a}$, or the initial CCG rate (CCG rate at initial crack length, $a_{0}$ ), $\dot{a}_{0}$, respectively. The initial CCG rate, $\dot{a}_{0}$, for a given value of $C^{*}$ may be estimated to be $(n+1)$ times less than the steady state value [8], hence the $\mathrm{CCl}$ time is estimated from

$$
\frac{\Delta a}{\dot{a}} \leq t_{i} \leq \frac{(n+1) \Delta a}{\dot{a}}
$$

Using the NSW-MOD steady state CCG rate prediction, the CCI time may predicted using 


$$
\left.\frac{\Delta a}{(n+1)\left(A r_{c}\right)^{\frac{1}{n+1}}}\left(\frac{I_{n}}{C^{*}}\right)^{\frac{n}{n+1}} \frac{\varepsilon_{f}^{*}}{\tilde{\varepsilon}_{e q}}\right|_{\max } \leq t_{i} \leq\left.\frac{\Delta a}{\left(A r_{c}\right)^{\frac{1}{n+1}}}\left(\frac{I_{n}}{C^{*}}\right)^{\frac{n}{n+1}} \frac{\varepsilon_{f}^{*}}{\tilde{\varepsilon}_{e q}}\right|_{\max }
$$

\section{Comparison of $\mathrm{CCl}$ and CCG Test Results}

A total of three tests have been performed on the DEN $(T)$ specimen geometry. Details of these tests are provided in Table 1 where $a_{0}$ and $a_{f}$ are the initial and final crack lengths, respectively, $\Delta a$ the total crack extension during the tests, $K\left(a_{0}\right)$ the stress intensity factor at the initial crack length, $\sigma_{r e f}$ the plane strain reference stress of the cracked geometry based on the von Mises equivalent stress and $\sigma_{0.2}$ the $0.2 \%$ proof strength of the material. Also included in Table 1 are results from the long term $C(T)$ tests and tests on the SEN(B) and CS(T) geometry, as detailed in [2]. The transition time, $t_{T}$, noted in Table 1, provides an estimate of time for $C^{*}$ dominance at the crack tip [4] and $t_{0.2}$ is the time for a crack extension of $0.2 \mathrm{~mm}$. Since the $\operatorname{DEN}(T)$ specimens possess two crack fronts, details for both cracks are specified. However, the fatigue precracking process has caused the initial lengths for crack 1 and crack 2 to differ. This has led to the shorter crack (crack 2) not initiating (i.e. amount of creep crack extension $<0.2 \mathrm{~mm}$ ) for all $\mathrm{DEN}(\mathrm{T})$ tests. Note that the solutions used for $K$ and $\sigma_{r e f}$ [8] assume that both cracks are of equal length. The reference stress of the cracked specimen normalised by the $0.2 \%$ proof strength is a measure of the extent of plasticity in the specimen. This ratio, $\sigma_{r e f} / \sigma_{0.2}$, has exceeded unity for the shorter term tests in Table 1 . The transition times are a very small fraction of the $\mathrm{DEN}(\mathrm{T})$ specimen test durations and less than $10 \%$ of the long term $\mathrm{C}(\mathrm{T})$ tests' duration. The normalised transition times for the SEN(B) and CS $(\mathrm{T})$ test are similarly around 10\%.

The long term $\mathrm{C}(\mathrm{T})$ tests, were loaded to a $\sigma_{\text {ref }} / \sigma_{0.2}$ ratio of $0.76-0.78$ in comparison to the long term $\mathrm{DEN}(\mathrm{T}) 2$ specimen test where, $\sigma_{r e f} / \sigma_{0.2}$ is just under unity. However, the highly constrained $\mathrm{C}(\mathrm{T})$ specimens have failed in almost half the time of the $\mathrm{DEN}(\mathrm{T})$ geometry.

The crack extensions and load line displacements (LLD) resulting from the $\mathrm{DEN}(\mathrm{T})$ tests are plotted against time normalised by test duration, $t_{f}$, in Figure 1 (a) and (b) respectively. Results from both cracks are shown for the long term test $\mathrm{DEN}(T) 2$. Crack 1 on test $\mathrm{DEN}(T) 2$ has a relatively short initiation time, defined as the time for a small measurable crack extension of $0.2 \mathrm{~mm}$, and grows relatively rapidly. In fact the normalised initiation time for $\operatorname{DEN}(T) 2$ crack 1 is less than a third of that for the other $\operatorname{DEN}(T)$ tests (see Table 1). A typical LLD plot is observed in Figure 1 (b) for specimens $\operatorname{DEN}(\mathrm{T}) 1$ and 3 i.e. a decelerating displacement rate region followed by a steady state region and finally accelerated displacement rate. However the LLD trace of specimen DEN(T) 2 is somewhat atypical. There is an initially large LLD rate which decelerates until 
$t / t_{f}$ is approximately 0.07 then accelerates again and decelerates towards a steady state from $t / t_{f}$ of approximately $0.4-0.6$. This unusual behaviour may be due to the influence of the small amount of growth in crack 2 and possible primary creep effects. Note that the tests have been stopped after the onset of unstable crack growth. Specimen DEN(T) 3 has been stopped after a relatively short crack extension compared to $\operatorname{DEN}(T) 1$ and $\operatorname{DEN}(T)$ 2, thus the final LLD in DEN(T) 3 is significantly less than $\operatorname{DEN}(T) 1$ and $\operatorname{DEN}(T) 2$.

The CCG rates of the tests identified in Table 1, are compared to those of a range of specimen geometries and test durations in Figure 2 (details of the other test are provided in [2, 9]). Only data for the relatively high constraint SEN(B) and CS(T) geometries are included in Figure 2 for clarity. However note that, as shown in [2, 9], data for relatively short term tests on three $\operatorname{SEN}(T)$ and five $M(T)$ specimen geometries (which were of duration 380-600 hrs and 300-1220 hrs, respectively) fall into the short term C(T) data band. Note that only data points which are considered valid for correlation with the $C^{*}$ parameter [4] are included in this figure. Also shown in Figure 2 are the plane stress and plane strain prediction lines from the NSW-MOD model (Eqn (3)) for $316 \mathrm{H}$ at $550{ }^{\circ} \mathrm{C}$. The material and model constants used in these analyses are shown in

Table 2 and Table 3, respectively [2]. As can be seen the long term $C(T)$ data (open square symbols) experience a higher creep crack growth rate for a given value of $C^{*}$, compared to short term (thus high $C^{*}$ ) tests, and the data is in agreement with the plane strain NSW-MOD prediction line. The CCG rates of the long term $\mathrm{DEN}(\mathrm{T})$ however is comparable to those of the shorter term $\mathrm{DEN}(\mathrm{T})$ geometries and the steady state crack growth region (signified by a power-law correlation between CCG rate and $C^{*}$ which appears as a straight line on a log-log plot) falls close to the plane stress NSW-MOD prediction line. It can also be seen that the CCG data the short term $C(T)$ data fall around the plane stress NSW-MOD prediction.

CCG data for two tests on the relatively high constraint SEN(B) geometry are shown in Figure 2. The normalised reference stress values, $\sigma_{r e f} / \sigma_{0.2}$, of $\operatorname{SEN}(\mathrm{B}) 2$ was $20 \%$ higher than that of $\mathrm{SEN}(\mathrm{B}) 4$, both of which exceeded unity (see Table 1). The CCG data of the relatively longer term SEN(B) 4 test $\left(t_{f}>6500 \mathrm{hrs}\right.$ ), which corresponds to the lower $C^{*}$ values, falls between the plane stress and plane strain NSW-MOD prediction and tends to be higher, for a given value of $C^{*}$ than the short term $\mathrm{C}(\mathrm{T})$ data, which also contains data from the $M(T)$ and $\operatorname{SEN}(T)$ geometry. However, data for test SEN(B) 2 falls in the middle of the short term $\mathrm{C}(\mathrm{T})$ data band, indicating a loss of constraint in this geometry at higher levels of plasticity. The CS(T) data falls upon the SEN(B) 2 test data indicating a similar level of constraint for these two specimens which were tested at similar $\sigma_{r e f} / \sigma_{0.2}$ values. 
Note that the DEN(T) geometries exhibit significant tails prior to the attainment of steady state CCG behaviour, though data for a crack extension of less than $0.2 \mathrm{~mm}$, which are considered to comprise the transient CCG regime where damage is building up to a steady state at the crack tip [4] have been excluded. The tail appears to elongate as the test duration and thus applied load decreases. A tail of this shape may be related to primary creep effects whilst damage builds up at the crack tip. Primary creep has been found to be more pronounced for this material and temperature at low stresses [10], which may explain why tests at relatively low load on the low constraint $\mathrm{DEN}(\mathrm{T})$ specimen, with therefore relatively low crack tip stress values, show significantly longer tails than the other tests in Figure 2.

The $C^{*}$ values of the longer term (lower load) test $\mathrm{DEN}(\mathrm{T}) 2$ are initially greater than that of the shorter term test $\mathrm{DEN}(\mathrm{T}) 3$, as can be seen in Figure 2. This can be explained for these two specimens, of equal dimensions, by examining the LLD rate vs. crack length data and noting that $C^{*}$ increases with load, LLD rate and crack length [4]. The initially high LLD rate exhibited in the $\mathrm{DEN}(\mathrm{T}) 2$ test compared to $\mathrm{DEN}(\mathrm{T}) 3$ compensates for the lower load applied to $\mathrm{DEN}(\mathrm{T}) 2$ causing it to have the higher $C^{*}$ value for a significant fraction of the tests' data. Eventually the $C^{*}$ value of $\mathrm{DEN}(\mathrm{T}) 2$ becomes less than that of $\mathrm{DEN}(\mathrm{T}) 3$, as expected.

The $\mathrm{CCl}$ times from these tests are correlated with the $C^{*}$ parameter calculated at the point of initiation in Figure 3(a) and (b) where the $\mathrm{CCl}$ time has been defined as the time for a crack extension of 0.2 and $0.5 \mathrm{~mm}$, respectively. All data the data from [2, 9] are included in Figure 3. Also shown in Figure 3 are the plane stress and plane strain NSW-MOD predictions based on the initial CCG rate, $\dot{a}_{0}$, and steady state CCG rate, $\dot{a}_{s}$ (see Eqn (5)). In Figure 3(a) it can be seen that the long term DEN(T) test (open symbol) falls close to the plane stress prediction based on the initial CCG rate, and the long term $C(T)$ test data fall close to the predictions based on $\dot{a}_{s}$, one of which is coincident with the plane strain prediction line. For $\Delta a=0.5 \mathrm{~mm}$, Figure $3(\mathrm{~b})$, the long term $\mathrm{C}(\mathrm{T})$ data fall about the plane strain prediction based on $\dot{a}_{s}$ indicating that steady state creep deformation and damage conditions have been achieved. For a given value of $C^{*}$ the $\mathrm{CCl}$ time of the long term $\mathrm{DEN}(\mathrm{T})$ geometry is generally in line with that of the tests on a variety of geometries of relatively short duration, whilst the long term $C(T)$ test generally initiate sooner.

\section{Discussion}

The long term $\mathrm{C}(\mathrm{T})$ data exhibit higher $\mathrm{CCG}$ rates and shorter $\mathrm{CCl}$ times, for a given value of $C^{*}$, compared to short term tests on the $\mathrm{C}(\mathrm{T})$ geometry, and generally agree with the plane strain prediction lines for $\mathrm{CCl}$ 
and CCG. The CCI and CCG behaviour of the long term DEN(T) test is however similar to that of the shorter term $\operatorname{DEN}(T)$ tests. This result is consistent with that observed in [11], which found that the CCG rate relationship of the relatively low constraint circumferentially-cracked bar (CCB) specimen was unaffected by test duration even for a wide range of $C^{*}$ values from less than $1 \times 10^{-6} \mathrm{MPamh}^{-1}$ to over $0.1 \mathrm{MPamh}^{-1}$.The $\mathrm{CCl}$ and $\mathrm{CCG}$ data from various specimen geometries (except for the long term $\mathrm{C}(\mathrm{T})$ data), follow the same trend and fall within the same experimental data band as the short term tests on the $C(T)$ geometry. Tests on SEN(B) 4 and $C S(T)$ which are more highly constrained geometries than the $\mathrm{DEN}(\mathrm{T}), \mathrm{SEN}(\mathrm{T})$ and $\mathrm{M}(\mathrm{T})$, may show intermediate CCG rates at relatively low $C^{*}$ values. The value of the ratio $\sigma_{\text {ref }} / \sigma_{0.2}$, assuming plane strain conditions, for the short term $\mathrm{C}(\mathrm{T})$ test specimens were either approximately equal to or greater than unity and greater than unity for all the alternative geometries (excluding $\operatorname{DEN}(T) 2$ ), indicating that significant amounts of plasticity are present in these specimens. Plasticity causes a loss of constraint in a specimen thus there is no clear geometric constraint effects between the specimen geometries at high $C^{*}$ values. The only distinct difference in CCG rate behaviour observed is for the high constraint $C(T)$ long term tests. Further long term tests on high constraint geometries may be needed to validate this behaviour. As stated above, the crack tip solutions used for the specimens with two crack fronts assume that both cracks are of equal length. However, only one crack front has shown significant growth in the $\mathrm{DEN}(\mathrm{T})$ specimen tests and therefore the behaviour may be more like that on an $\operatorname{SEN}(T)$ specimen. The $D E N(T)$ data have also been analysed using SEN(T) specimen solutions, but the difference in the results obtained are relatively small, thus not shown.

\section{Conclusions}

Long term creep crack initiation $(\mathrm{CCl})$ and growth (CCG) testing has been performed on the relatively low constraint double edge notch tension specimen, $\mathrm{DEN}(\mathrm{T})$, of Type $316 \mathrm{H}$ steel at $550{ }^{\circ} \mathrm{C}$. The results are compared to short term tests on a range of specimen geometries, long term tests on the compact tension, $C(T)$, geometry and predictions from CCG models. The long term $C(T)$ test data follow the plane strain prediction lines and the CCG rates are higher for a given value of $C^{*}$ compared to the long and short term tests on a variety of specimen geometries (which tend to resemble the plane stress predictions). The relatively low constraint $\mathrm{DEN}(\mathrm{T})$ geometry exhibits similar crack growth behaviour at high and low $C^{*}$ values, indicating little variation in specimen constraint, and follows the plane stress predictions. The DEN(T) specimen tests exhibit significant tails prior to the attainment of steady state CCG behaviour, which may be attributed to primary creep effects. This is especially the case for the longer term test data. The short term tests are generally loaded to a reference stress level that is greater than the yield strength of $316 \mathrm{H}$ steel at 
$550^{\circ} \mathrm{C}$. Plasticity causes a loss of constraint in a specimen and hence no clear geometric constraint effects have been found between the short term tests (at high $C^{*}$ ) for the various low and high constraint specimen geometries and the long term low constraint geometries. The only distinct difference in cracking behaviour is observed for the high constraint $\mathrm{C}(\mathrm{T})$ long term tests. Further long term tests on high constraint geometries may be needed to validate this behaviour.

\section{References}

1. Dean, D. W. and Gladwin, D. N., Creep Crack Growth Behaviour of Type 316H Steels and Proposed Modifications to Standard Testing and Analysis Methods, The International Journal of Pressure Vessels and Piping, 2007, 84(6), pp. 378-395.

2. Davies, C. M., Mueller, F., Nikbin, K. M., O'Dowd, N. P. and Webster, G. A., Analysis of Creep Crack Initiation and Growth in Different Geometries for 316H and Carbon Manganese Steels, Journal of ASTM International, 2006, 3(2), DOI : 10.1520/JAl13223.

3. Webster, G. A., Ainsworth, R. A., High Temperature Component Life Assessment, 1st ed, 1994, London: Chapman and Hall.

4. ASTM, E1457-07: Measurement of Creep Crack Growth Times in Metals, in Annual Book of ASTM Standards, Vol. 03.01, 2007, ASTM International, pp. 1012-1035.

5. Yatomi, M., Nikbin, K. M., O'Dowd, N. P. and Webster, G. A., Theoretical and Numerical Modelling of Creep Crack Growth in a Carbon-Manganese Steel, Engineering Fracture Mechanics, 2006, 73(9), pp. $1158-1176$.

6. Shih, C. F., Tables of Hutchinson-Rice-Rosengren Singular Field Quantities, MRL E-Providence, Ri, Brown University Technical Report, MRL E-147, June, 1983.

7. Cocks, A. C. F. and Ashby, M. F., Intergranular Fracture During Power-Law Creep under Multi-Axial Stress, Metal Science, 1980, 14, pp. 395-402.

8. Webster, G. A. and Ainsworth, R. A., High Temperature Component Life Assessment, 1st ed, 1994, London: Chapman and Hall.

9. Davies, C. M., Crack Initiation and Growth at Elevated Temperatures in Engineering Steels, Ph.D. Thesis, Department of Mechanical Engineering, Imperial College London, 2006.

10. Hayhurst, D. R., Constitutive Equations for Time Independent Plasticity and Creep of 316 Stainless Steel at $550^{\circ} \mathrm{C}$, The International journal of pressure vessels and piping, 2003, 80(2), pp. 97-109. 
11. Budden, P. J. and Dean, D. W., Constraint Effects on Creep Crack Growth, in Proceedings of the Creep8 Eighth International Conference on Creep and Fatigue at Elevated Temperatures, July 22-26, 2007, San Antonio, Texas, USA, CREEP2007-26104.

\section{Tables}

Table 1: Test details

\begin{tabular}{|c|c|c|c|c|c|c|c|c|c|}
\hline Specimen & $a_{0} / W$ & $a_{f} / W$ & $\begin{array}{c}\Delta a \\
(\mathrm{~mm})\end{array}$ & $\begin{array}{c}K\left(a_{0}\right) \\
\mathrm{MPa} \sqrt{\mathrm{m}}\end{array}$ & $\begin{array}{c}\text { Load, } P \\
\text { (kN) }\end{array}$ & $\begin{array}{c}\sigma_{r e f} / \sigma_{0.2} \\
\text { Plane Strain }\end{array}$ & $\begin{array}{c}\text { Test } \\
\text { Duration, } \\
t_{f}(\mathrm{~h})\end{array}$ & $\begin{array}{l}\frac{t_{T}}{t_{f}} \\
(\%)\end{array}$ & $\begin{array}{l}\frac{t_{0.2}}{t_{f}} \\
(\%)\end{array}$ \\
\hline $\begin{array}{l}\text { DEN(T) } 1 \\
\text { Crack } 1\end{array}$ & 0.39 & 0.93 & 6.7 & 22.6 & \multirow{2}{*}{45.0} & 1.18 & \multirow{2}{*}{7,610} & 2.0 & 31.2 \\
\hline $\begin{array}{l}\operatorname{DEN}(\mathrm{T}) 1 \\
\text { Crack } 2\end{array}$ & 0.29 & 0.29 & 0.0 & 19.1 & & 1.09 & & - & - \\
\hline $\begin{array}{l}\operatorname{DEN}(\mathrm{T}) 2 \\
\text { Crack } 1\end{array}$ & 0.33 & 0.81 & 6.0 & 18.0 & \multirow[t]{2}{*}{39.4} & 0.98 & \multirow[t]{2}{*}{32,515} & 0.4 & 9.5 \\
\hline $\begin{array}{l}\text { DEN(T) } 2 \\
\text { Crack } 2\end{array}$ & 0.26 & 0.27 & 0.1 & 15.9 & & 0.95 & & - & - \\
\hline $\begin{array}{l}\text { DEN(T) } 3 \\
\text { Crack } 1\end{array}$ & 0.32 & 0.43 & 1.4 & 19.2 & \multirow[t]{2}{*}{43.0} & 1.06 & \multirow[t]{2}{*}{13,600} & 1.6 & 37.3 \\
\hline $\begin{array}{l}\text { DEN(T) } 3 \\
\text { Crack } 2\end{array}$ & 0.29 & 0.29 & 0.0 & 19.2 & & 1.04 & & - & - \\
\hline $\mathrm{C}(\mathrm{T}) 1$ & 0.55 & 0.62 & 3.0 & 26.6 & 7.86 & 0.78 & 16,567 & 9.3 & 9.4 \\
\hline $\mathrm{C}(\mathrm{T}) 20$ & 0.54 & 0.66 & 4.5 & 26.0 & 7.75 & 0.76 & 17,832 & 6.6 & 21.8 \\
\hline $\mathrm{SEN}(\mathrm{B}) 2$ & 0.33 & 0.43 & 2.4 & 34.0 & 9.0 & 1.36 & 641 & 10.4 & 84.2 \\
\hline SEN(B) 4 & 0.33 & 0.43 & 2.5 & 28.3 & 7.6 & 1.13 & 6522 & 9.2 & 52.6 \\
\hline $\mathrm{CS}(\mathrm{T})$ & 0.23 & 0.30 & 1.6 & 34.1 & 16.5 & 1.09 & 3830 & 14.1 & 29.8 \\
\hline
\end{tabular}


Table 2: Material for $316 \mathrm{H}$ steel at $550^{\circ} \mathrm{C}$.

\begin{tabular}{|c|c|}
\hline$E$ & $140 \mathrm{GPa}$ \\
\hline$\sigma_{0.2}$ & $170 \mathrm{MPa}$ \\
\hline$A^{\dagger}$ & $1.56 \times 10^{-35}$ \\
\hline$n$ & 11.95 \\
\hline$r_{c}$ & $50 \mu \mathrm{m}$ \\
\hline$\varepsilon_{f}^{*}$ & $21 \%$ \\
\hline
\end{tabular}

${ }^{\dagger}$ stress in MPa, time in hours

${ }^{\ddagger}$ creep failure strain, determined from reduction of area in a uniaxial creep test

Table 3: NSW-MOD model values used for $316 \mathrm{H}$ at $550^{\circ} \mathrm{C}$.

\begin{tabular}{ccc}
\hline & Plane stress & Plane strain \\
\hline$\widetilde{\varepsilon}_{e q}(\theta, n)$ & 1 & 0.3 \\
\hline$\varepsilon_{f}^{*}(\theta, n) / \varepsilon_{f}$ & 0.5 & 0.03 \\
\hline$\varepsilon_{f}\left(\widetilde{\varepsilon}_{e q} / \varepsilon_{f}^{*}\right)_{\max }$ & 2 & 10 \\
\hline$I_{n}$ & 3.1 & 4.4 \\
\hline$\dot{a}_{\max }^{P \varepsilon} / \dot{a}_{\max }^{P \sigma}$ & & 3.54 \\
\end{tabular}

\section{Figures}
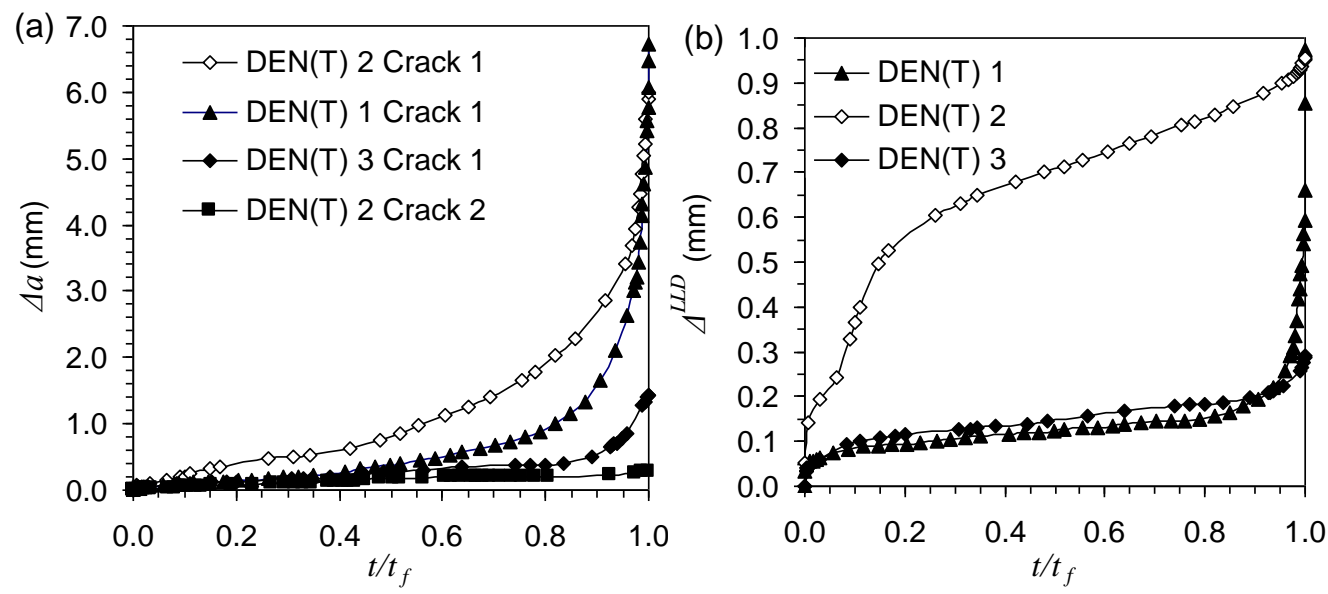

Figure 1: Comparison of (a) creep crack extensions and (b) creep load line displacements of three tests on the $\operatorname{DEN}(T)$ geometry 


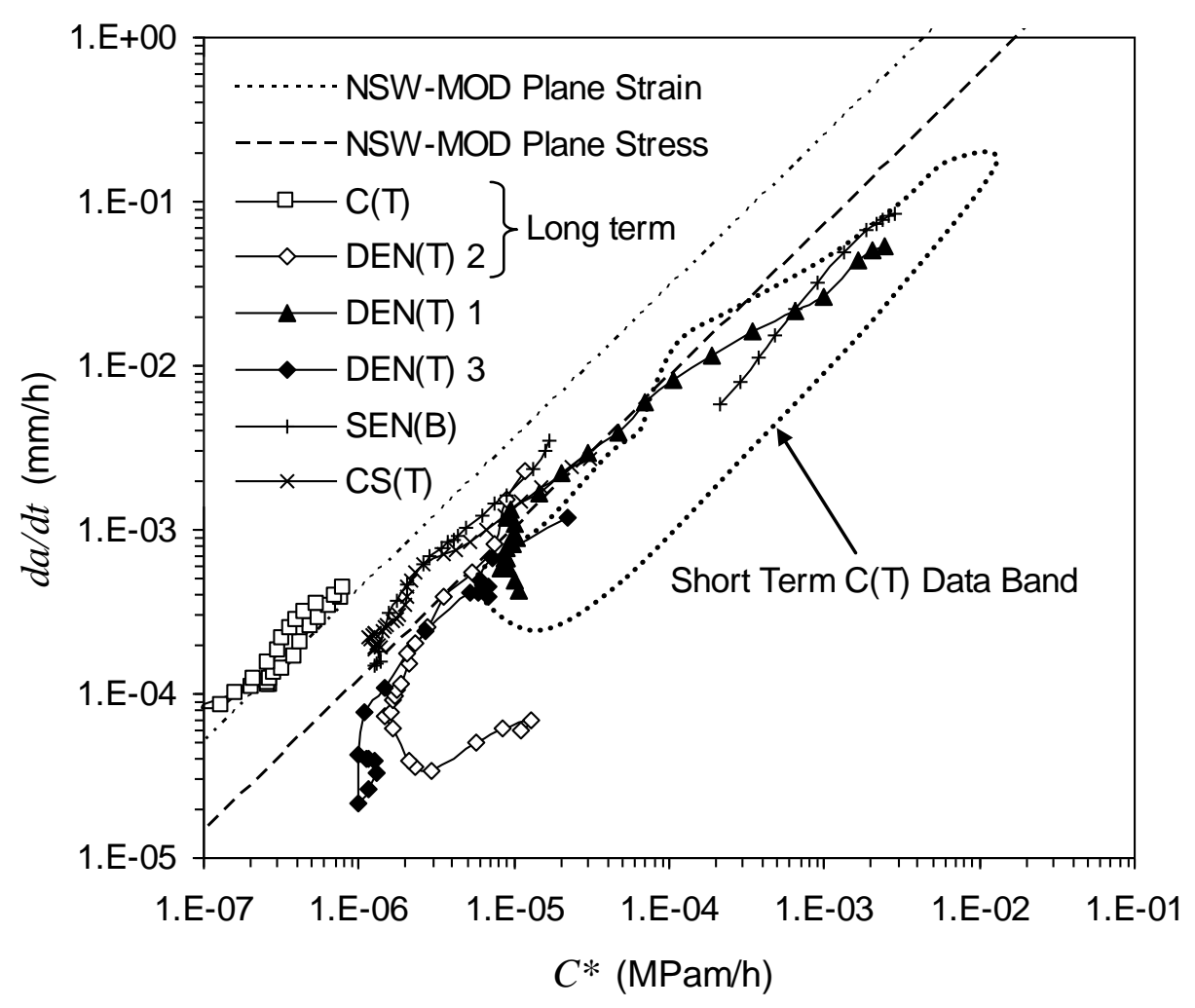

Figure 2: Comparison of creep crack growth rates from short and long term tests of various specimen geometries with the modified NSW model's predictions. 

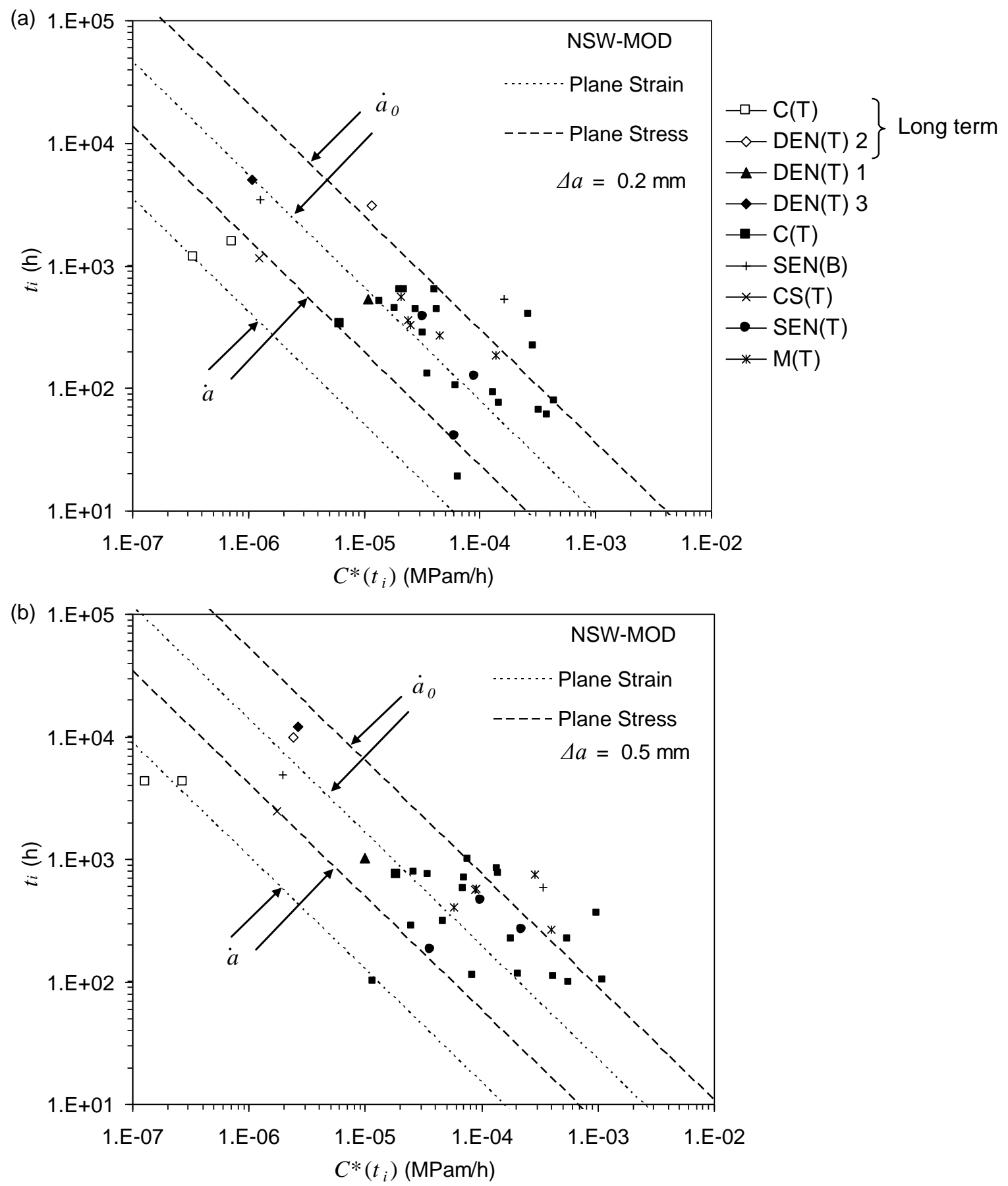

Figure 3: Comparison of creep crack initiation times from short and long term tests of various specimen geometries with the modified NSW model's predictions. 